\title{
Prevalence and antimicrobial
} of Mekelle University, North Ethiopia

\author{
Atsebaha Gebrekidan Kahsay ${ }^{*}$, Dawit Gebreegziabher Hagos, Getahun Kahsay Abay \\ and Tadele Araya Mezgebo
}

\begin{abstract}
Objective: The objective of this study was to determine the prevalence of methicillin-resistant Staphylococcus aureus and antimicrobial susceptibility patterns among janitors working at Mekelle University, Tigray, Northern Ethiopia.

Result: The overall prevalence of S. aureus and MRSA in the present study were 17.97\% (69/384) and 6.25\% (24/384) respectively. Although not statistically significant, the prevalence of MRSA among janitors working in the medical area $(9.7 \%, 10 / 103)$ was two times higher than the non-medical area $(4.9 \%, 14 / 281)$. Janitors who had more service year and who were unable to read and write were found with high isolates of MRSA. Nasal carriage of MRSA among janitors who work in the hospital and who were hospitalized in the last 3 months and those who had exposure to wastes and body fluids were $13(37.1 \%)$ and 10 (38.5\%) respectively. Majority of the isolates of S. aureus were sensitive to ciprofloxacin (67; 97\%), doxycycline (56; 81\%), erythromycin (54; 78\%), chloramphenicol (50; 72.5\%) and cefoxitin (45; 65.2\%). Sixty-seven of the 69 (97\%) were resistant to penicillin. Of the 69 isolates of S. aureus, 22 (31.9\%) showed multidrug resistant. Fourteen were resistant to three antimicrobials, 2 were resistant to four antimicrobials, and 7 were resistant to five antimicrobials.
\end{abstract}

Keywords: Mekelle University, Methicillin resistant Staphylococcus aureus, Janitors, Antimicrobial susceptibility tests

\section{Introduction}

Staphylococcus aureus, a Gram-positive spherical-shaped bacterium, predominantly colonizes the skin and nasal mucosa of healthy individuals globally [1]. Approximately $28 \%$ of healthy adult individuals have their anterior nares persistently colonized with this bacterium (https://www. ncbi.nlm.nih.gov/pmc/articles/PMC172932) [2]. Person to person transmission of $S$. aureus occurs mostly through contact with fluids from infected skin abrasions [3]. Infections due to $S$. aureus range from simple skin infections to fatal bacteremia and pneumonia [1]. $S$. aureus contributes to one-third of surgical site infections

*Correspondence: atseba_mu@yahoo.com

Department of Medical Microbiology and Immunology, Institute

of Biomedical Sciences, College of Health Sciences, Mekelle University,

Mekelle, Ethiopia and close to a quarter of ventilator-associated pneumonia [4]. Between 2001 and 2009, the S. aureus skin and soft tissue infections associated hospitalization has increased from 39 to $51 \%$ in hospitals of USA [5].

With the emergence of methicillin-resistant $S$. aureus (MRSA) first recognized from hospitalized patients in 1960 [4], the treatment of Staphylococcal infections has become more challenging [5]. Until 1990, could only be described as a hospital-acquired infection [6]. Subsequently, MRSA has become a major global public health problem in both hospitals [6-9] and community [10-13] settings globally. Among hospitals and non-medical janitors in Taiwan, 3.6 and $1.3 \%$ have MRSA in their nares respectively [14]. In Pakistan, $13.6 \%$ of sanitary and $2.1 \%$ administrative workers were found to have MRSA in their nares respectively [15]. The nasal carriage of MRSA 
among 600 randomly selected health workers in Iran was $5.3 \%[16]$.

Thirty-four (28.8\%) and 15 (12.7\%) healthcare workers in Dessie-Ethiopia had their anterior nares colonized with $S$. aureus and MRSA respectively [17]. Eighty-five (59\%) and 44 (28.9\%) in patients in Jimma-Ethiopia had their anterior nares colonized with S. aureus and MRSA respectively [18].

At Mekelle Hospital-Ethiopia, the nasal and hand carriage of MRSA among healthcare workers was 20.3\% [19].

In Ethiopia, as to our knowledge, despite its importance, there is no published data that indicates the prevalence of MRSA and antimicrobial susceptibility patterns among janitors of any institution.

Therefore, this research project assessed the prevalence of MRSA and its antimicrobial susceptibility patterns among janitors working in Mekelle University; with a view to providing information to aid the design of appropriate prevention strategies.

\section{Main text \\ Materials and methods \\ Study area and study design}

Mekelle University is one of the largest Universities in Ethiopia. It has more than 30 thousand first-degree, second-degree and third-degree annual students in the five campuses [20]. It conducts teaching, research, and community activities. There are 576 janitors working at Mekelle University (155 from one campus in Ayder comprehensive specialized hospital and 421 from other four campuses of the University. A cross-sectional study was conducted from January to May 2016.

\section{Sample size and sampling technique}

A total of 384 janitors (103 from medical and 281 from non-medical) were recruited to participate in the study. The sample size was calculated using single proportion formula $(P=0.5, Z \alpha / 2=0.196, C I=95)$. Simple random sampling technique was used to select 384 study participants. Study participants who had nasal bleeding at the time of data collection were excluded because rolling of swab may aggravate bleeding.

\section{Data collection and processing}

Trained data collectors were recruited to collect the socio-demographic, clinical and other factors from consenting participants using a standardized questionnaire. The questionnaire could be self-administered (for literate participants) or interview-administer (for participants unable to read and write their mother language).

\section{Sample collection, transport, and processing}

Using aseptic procedures, trained study assistants took nasal swab samples from both anterior nares of the study participants which were transported to Mekelle University College of Health Sciences department of medical microbiology laboratory within $30 \mathrm{~min}$ of collection. Upon arrival, specimens were inoculated on to Mannitol salt agar (HI Media Laboratories, Pvt. Mumbai, India) and incubated at $37{ }^{\circ} \mathrm{C}$ for $24 \mathrm{~h}$. After incubation, the presence of $S$. aureus was confirmed by golden yellowish colonies, Gram stain and a biochemical test using slide coagulase test $[21,22]$.

\section{Antimicrobial susceptibility tests}

Isolates identified as $S$. aureus were subjected to antimicrobial susceptibility tests using the Kirby Bauer disk diffusion method as described by CLSI [23]. Six antimicrobials were used; these were penicillin (10 units), erythromycin $(15 \mu \mathrm{g})$, chloramphenicol $(30 \mu \mathrm{g})$, doxycycline $(30 \mu \mathrm{g})$, ciprofloxacin $(5 \mu \mathrm{g})$ and cefoxitin $(30 \mu \mathrm{g})$. Three to five colonies of $S$. aureus were picked from the nutrient agar to make a suspension that was standardized to $0.5 \mathrm{McF}$ arland standards. Using sterile applicator cotton swab, standardized suspensions were swabbed on to the Muller Hinton agar. The antimicrobial discs were placed then on the Muller Hinton agar within 20 min using aseptic technique. The Muller Hinton agar plates were incubated at $35{ }^{\circ} \mathrm{C}$ for $18 \mathrm{~h}$. After this, the diameter of the "zone of inhibition" around the antibiotic discs was measured using calipers and reported as sensitive, intermediate and resistance [21-23].

Methicillin resistance $S$. aureus was confirmed by $30 \mu \mathrm{g}$ cefoxitin disc. A "zone of inhibition" of $\leq 21 \mathrm{~mm}$ was considered as methicillin-sensitive and a "zone of inhibition" of $>22$ as methicillin-resistant.

\section{Quality control}

Each lot and shipment of the medium was checked for expiration dates prior to use as part of quality control. The performance of the media and antibiotic discs were evaluated using positive controls (S. aureus, ATCC-25923) and negative controls (Escherichia coliATCC-25922) [23].

\section{Statistical analysis}

Frequency and percentage were used to summarize categorical data. Chi square statistics were used to describe associations between various participants' characteristics and Staphylococcus nasal carriage. The level of significance was set at $\alpha=0.05$ using the two-tailed method. 
SPSS for Windows Version 20 software was used for the statistical analysis of the collected data.

\section{Ethical consideration}

Ethical approval was obtained from the Ethical Review Committee of Mekelle University, College of Health Sciences with a proposal number of ERC 0682/2015. Informed consent was collected from each study participants after they understood the aim of the study. As the janitors were outsourced to a private company, permission was collected from the private limited company.

\section{Results}

\section{Socio-demographic characteristics}

Three hundred and eighty-four participants were recruited. Their mean age was $21( \pm 4.97)$ years and all $(100 \%)$ were female. The majority $(85.2 \% ; 327)$ were aged $18-24$ years. The majority were single $(81.8 \%)$, had attained a high school education; grade 9-12 (53.1\%) and lived with children aged $<15$ years $(52.6 \%)$.

Majority (63\%) had served as a janitor for less than 1 year, in a non-medical area (73.1\%), did not suffer from allergic rhinitis (95.3\%), had not had a skin infection (97.1\%), nor a wound infection $(94.8 \%)$, nor been hospitalized (64.3\%) in the 3 months preceding the interview. The majority (73.2\%) reported no history of exposure to waste and body fluids (Table 1).

\section{Isolation of S. aureus from participant's samples}

Samples were collected from the anterior nares of all participants; S. aureus was cultured from 69 (17.97\%) of the samples. Of the 69 isolates, $25.2 \%(26 / 103)$ were recovered from janitors that worked in medical areas and $15.3 \%(43 / 81)$ from those that worked in non-medical areas of the University (Table 1).

\section{Prevalence of MRSA among janitors working at Mekelle University}

Among participants with positive isolates $(\mathrm{n}=69), 24$ (34.8\%) had methicillin resistant $S$. aureus. Ten of the 26 isolates (38.5\%) were among janitors working in medical areas where as $14 / 43(32.6 \%)$ was working in non-medical areas. The overall prevalence of MRSA was $6.25 \%$ $(24 / 384)$ (Table 1).

\section{Antimicrobial susceptibility patterns of $S$. aureus isolates}

All the $69 \mathrm{~S}$. aureus isolates were subjected to antimicrobial susceptibility tests against seven antimicrobials. Majority of the isolates of $S$. aureus were sensitive to ciprofloxacin $(67 ; 97 \%)$, doxycycline $(56 ; 81 \%)$, erythromycin $(54 ; 78 \%)$, chloramphenicol $(50 ; 72.5 \%)$ and cefoxitin (45; 65.2\%). Sixty-seven of the 69 (97\%) were resistant to penicillin. About one-third 24 (34.8\%) of the isolates were resistant to cefoxitin. Of the 45 methicillin susceptible S. aureus, 2 (4.4\%), 5 (11.1\%), 6 (13.3\%), 6 (13.3\%) and 43 (95.6\%) were resistant to ciprofloxacin, doxycycline, erythromycin, chloramphenicol, and penicillin respectively (Table 2).

\section{Multidrug resistance (MDR) isolates of $S$. aureus}

Of the 69 isolates of $S$. aureus, 22 (31.9\%) isolates showed MDR. Fourteen were resistant to three antimicrobials, 2 were resistant to four antimicrobials, and 7 were resistant to five antimicrobials (Table 3 ).

\section{Factors associated with MRSA colonization of the anterior nares among janitors at Mekelle University}

A significantly higher proportion of participants with $S$. aureus colonization was found among participants who were unable to read or write compared to those who had attained junior secondary, high school and diploma level education (62.5\% vs. $47.1,18.2$, and $45.5 \%$ respectively); among participants that had served as janitors for more than 2 years compared to those who had served for less than 1 year and for between one and 2 years $(62.5 \%$ vs. $39.5 \%$ and $11.1 \%$ respectively) (Table 1 ).

Staphylococcus aureus was isolated from the nasal swab of one study participants who had allergic rhinitis and was resistant to cefoxitin/methicillin. Nasal carriages of MRSA among janitors who work in the hospital and who were hospitalized in the last 3 months and those who had exposure to wastes and body fluids were $13(37.1 \%)$ and $10(38.5 \%)$ respectively (Table 1$)$.

\section{Discussion}

The overall prevalence of $S$. aureus and MRSA in this study were $69(17.97 \%)$ and $24(6.25 \%)$. This is lower than the study carried out among hospital personals in Pakistan [15] and school children and prisoners in JimmaEthiopia [3], but similar to the study revealed from healthcare workers in Iran [16].

Staphylococcus aureus was found to be colonized in 26 (25.2\%) janitors working in medical and 43 (16\%) in nonmedical area, whereas MRSA revealed from 10 (9.7\%) in medical and $14(4.9 \%)$ non-medical area. This is higher than the study carried out in Taiwan [14]. This may be due to difference in personal hygiene.

Above $85 \%$ of the janitors working in the university were youth (18-24 years). The other below $15 \%$ was above 24 years and was found to be with high carriage of MRSA 4 (40\%). This is comparable with the study among prisoners in Jimma-Ethiopia [3]. Above $70 \%$ of the janitor were high school and diploma but high prevalence of MRSA $5(62.5 \%, \mathrm{P}=0.038)$ were revealed among janitors who were unable to read and write in which transmission may be high. This might be due to lack of awareness in 
Table 1 Prevalence of Staphylococcus aureus, MRSA, and MSSA among janitors of Mekelle University, 2016

\begin{tabular}{|c|c|c|c|c|c|}
\hline & $\begin{array}{l}\text { Study subjects } \\
\mathrm{N}=384, \mathrm{~N}(\%)\end{array}$ & $\begin{array}{l}\text { Total S. aureus } \\
\text { isolates } \\
\mathrm{N}(\%), 69(17.97 \%)\end{array}$ & $\begin{array}{l}M^{M R S}{ }^{a}, N=24 \\
N(\%)\end{array}$ & $\begin{array}{l}M S^{b} A^{b}, n=45 \\
N(\%)\end{array}$ & P value \\
\hline \multicolumn{5}{|l|}{ Age } & \multirow[t]{3}{*}{0.708} \\
\hline $18-24$ & $327(85.2)$ & $59(18)$ & $20(33.9)$ & $39(66.1)$ & \\
\hline$>24$ & $57(14.8)$ & $10(17.5)$ & $4(40)$ & $6(60)$ & \\
\hline \multicolumn{6}{|l|}{ Sex } \\
\hline Female & $384(100)$ & 69 & 24 & 45 & \multirow[t]{2}{*}{ - } \\
\hline Male & $0(0)$ & - & - & - & \\
\hline \multicolumn{5}{|l|}{ Marital status } & \multirow[t]{4}{*}{0.166} \\
\hline Single & $314(81.8)$ & $55(17.5)$ & $22(40)$ & $33(60)$ & \\
\hline Married & $52(13.5)$ & $11(21.2)$ & $2(18.2)$ & $9(81.8)$ & \\
\hline Divorced & $18(5.7)$ & $3(16.7)$ & 0 & $3(100)$ & \\
\hline \multicolumn{5}{|l|}{ Educational status } & \multirow[t]{5}{*}{0.038} \\
\hline Unable to read and write & $25(6.5)$ & $8(32)$ & $5(62.5)$ & $3(37.5)$ & \\
\hline Junior secondary school & $84(21.9)$ & $17(20.2)$ & $8(47.1)$ & $9(52.9)$ & \\
\hline High school & $204(53.4)$ & $33(16.2)$ & $6(18.2)$ & $27(81.8)$ & \\
\hline Diploma & $71(18.5)$ & $11(15.5)$ & $5(45.5)$ & $6(54.5)$ & \\
\hline \multicolumn{5}{|l|}{ Live with children } & \multirow[t]{3}{*}{0.054} \\
\hline Yes & $202(52.6)$ & $28(13.9)$ & $6(21.4)$ & $22(78.6)$ & \\
\hline No & $182(47.4)$ & $41(22.5)$ & $18(43.9)$ & $23(56.1)$ & \\
\hline \multicolumn{5}{|l|}{ Service as a janitor in year } & \multirow[t]{4}{*}{0.023} \\
\hline$<1$ & $242(63)$ & $43(17.8)$ & $17(39.5)$ & $26(60.5)$ & \\
\hline $1-2$ & $109(28.4)$ & $18(16.5)$ & $2(11.1)$ & $16(88.9)$ & \\
\hline$>2$ & $33(8.6)$ & $8(24.2)$ & $5(62.5)$ & $3(37.5)$ & \\
\hline \multicolumn{5}{|l|}{ Cleaning area } & \multirow[t]{3}{*}{0.286} \\
\hline Medical & $103(26.8)$ & $26(25.2)$ & $10(38.5)$ & $16(61.5)$ & \\
\hline None medical & $281(73.2)$ & $43(15.3)$ & $14(32.6)$ & $29(67.4)$ & \\
\hline \multicolumn{5}{|l|}{ Allergic rhinitis disease } & \multirow[t]{3}{*}{0.168} \\
\hline Yes & $18(4.7)$ & $1(5.6)$ & $1(100)$ & 0 & \\
\hline No & $366(95.3)$ & $68(18.6)$ & $23(33.8)$ & $45(66.2)$ & \\
\hline \multicolumn{5}{|c|}{ Respiratory infection (within last 3 months) } & \multirow[t]{3}{*}{0.168} \\
\hline Yes & $11(2.9)$ & $1(9.1)$ & $1(100)$ & 0 & \\
\hline No & $373(97.1)$ & $68(18.2)$ & $23(33.8)$ & $45(66.2)$ & \\
\hline \multicolumn{5}{|c|}{ Skin infection (within last 3 months) } & \multirow[t]{3}{*}{0.005} \\
\hline Yes & $11(2.9)$ & $4(36.4)$ & $4(100)$ & 0 & \\
\hline No & $373(97.1)$ & $65(17.4)$ & $20(30.8)$ & $45(69.2)$ & \\
\hline \multicolumn{5}{|c|}{ Wound present (within last 3 months) } & \multirow[t]{3}{*}{0.938} \\
\hline Yes & $20(5.2)$ & $6(30)$ & $2(33.3)$ & $4(66.7)$ & \\
\hline No & $364(94.8)$ & $63(17.3)$ & $22(34.9)$ & $41(65.1)$ & \\
\hline \multicolumn{5}{|c|}{ Hospital stay and hospitalization (within 3 months) } & \multirow[t]{3}{*}{0.676} \\
\hline Yes & $137(35.7)$ & $35(25.5)$ & $13(37.1)$ & $22(62.9)$ & \\
\hline No & $247(64.3)$ & $34(13.8)$ & $11(32.4)$ & $23(67.6)$ & \\
\hline Exposure to waste and fluic & & & & & 0.618 \\
\hline Yes & $103(26.8)$ & $26(25.2)$ & $10(38.5)$ & $16(61.5)$ & \\
\hline No & $281(73.2)$ & $43(15.3)$ & $14(32.6)$ & $29(67.4)$ & \\
\hline
\end{tabular}

$\mathrm{N}$ total isolates of MRSA, $\mathrm{n}$ total number of MSSA isolates

${ }^{a}$ Methicillin resistance $S$. aureus

${ }^{\mathrm{b}}$ Methicillin sensitive $S$. aureus 
Table 2 Antimicrobial susceptibility patterns of S. aureus isolates in Mekelle University, 2016

\begin{tabular}{|c|c|c|c|c|}
\hline \multirow{3}{*}{$\begin{array}{l}\text { Antimicrobial } \\
\text { drugs }\end{array}$} & \multicolumn{2}{|l|}{ S. aureus } & \multirow{3}{*}{$\begin{array}{l}\text { Total } \\
\mathrm{N}(\%)\end{array}$} & \multirow[t]{3}{*}{ P value } \\
\hline & MRSA, $N=24$ & MSSA, $n=45$ & & \\
\hline & N (\%) & N (\%) & & \\
\hline \multicolumn{5}{|l|}{ Ciprofloxacin } \\
\hline Susceptible & $24(100)$ & 43 (95.6) & $67(97.1)$ & 0.295 \\
\hline Resistance & - & $2(4.4)$ & $2(2.9)$ & \\
\hline \multicolumn{5}{|l|}{ Doxycycline } \\
\hline Susceptible & $16(66.7)$ & 40 (88.9) & $56(81.2)$ & 0.025 \\
\hline Resistance & $8(33.3)$ & $5(11.1)$ & $13(18.8)$ & \\
\hline \multicolumn{5}{|l|}{ Erythromycin } \\
\hline Susceptible & $15(62.5)$ & 39 (86.7) & $54(78.3)$ & 0.020 \\
\hline Resistance & $9(37.5)$ & $6(13.3)$ & $15(21.7)$ & \\
\hline \multicolumn{5}{|c|}{ Chloramphenicol } \\
\hline Susceptible & $11(45.8)$ & $39(86.7)$ & $50(72.5)$ & 0.000 \\
\hline Resistance & $13(54.2)$ & $6(13.3)$ & $19(27.5)$ & \\
\hline \multicolumn{5}{|l|}{ Cefoxitin } \\
\hline Susceptible & - & $45(100)$ & $45(65.2)$ & \\
\hline Resistance & $24(100)$ & - & $24(34.8)$ & \\
\hline \multicolumn{5}{|l|}{ Penicillin } \\
\hline Susceptible & - & $2(4.4)$ & $2(2.9)$ & 0.295 \\
\hline Resistance & $24(100)$ & 43 (95.6) & 67 (97.1) & \\
\hline
\end{tabular}

MRSA, methicillin resistance Staphylococcus aureus; MSSA, methicillin sensitive Staphylococcus aureus

Table 3 Multidrug-resistance isolates of S. aureus among janitors of Mekelle University, 2016

\begin{tabular}{|c|c|c|}
\hline \multirow{2}{*}{$\begin{array}{l}\text { Number of antimicrobial } \\
\text { resistance }\end{array}$} & \multicolumn{2}{|c|}{ Staphylococcus aureus isolates $(n=69)$} \\
\hline & $\begin{array}{l}\text { MDR patterns }(n=22 \\
31.9 \%)^{a}\end{array}$ & $\begin{array}{l}\text { Number } \\
\text { of isolates } \\
\text { (\%) }\end{array}$ \\
\hline \multirow[t]{6}{*}{ Three } & CIP, Pen, C & $1(1.4)$ \\
\hline & Fox, Pen, C & $5(17.2)$ \\
\hline & E, Doxy, Pen & $1(1.4)$ \\
\hline & Fox, E, Pen & $3(4.3)$ \\
\hline & Fox, Doxy, Pen & $1(1.4)$ \\
\hline & Doxy, Pen, C & $3(4.3)$ \\
\hline \multirow[t]{2}{*}{ Four } & E, Doxy, Pen, C & $1(1.4)$ \\
\hline & Fox, Doxy, Pen, C & $1(1.4)$ \\
\hline \multirow[t]{2}{*}{ Five } & Fox, E, Doxy, Pen, C & $6(21.4)$ \\
\hline & Fox, E, Doxy, CIP, C & $1(1.4)$ \\
\hline
\end{tabular}

a Fox, cefoxitin $(30 \mu \mathrm{g}) ;$, chloramphenicol $(30 \mu \mathrm{g})$; Ery, erythromycin $(15 \mu \mathrm{g})$; Pen, penicillin (10 unit); CIP, ciprofloxacin ( $1 \mu \mathrm{g})$; Dox, doxycycline $(30 \mu \mathrm{g})$

using safety measures available in the medical area during work (exposure to wastes) and may have hand nasal contact that can lead to increase the MRSA. About $62 \%$ of the participants were served below 1 year as a janitor, however, MRSA carriage was raised among the janitors who served above 2 years $5(62.5 \%, \mathrm{P}=0.023)$.

None of the participants were presented with underlying diseases except eighteen participants with allergic rhinitis and one of whom having allergic rhinitis had MRSA which is not statistically significant. This is different from a study conducted in Taiwan [14]. Janitors were also requested to respond to the occurrence of respiratory infection, skin infection and present of wound, hospital stay and hospitalization in the last 3 months. The carriage rate of MRSA among the janitors having respiratory, skin infection and present with wound were 1 (100\%), $4(100 \%)$ and $2(33.3 \%)$ respectively. This is unlike to the study reported from Taiwan [14].

MRSA isolates were $100 \%$ resistant to penicillin and cefoxitin which is similar to the study reported from Jimma [3]. 24 (100\%), 16 (66.7\%), 15 (62.5\%), and 11 (45.8\%) isolates of MRSA were sensitive to ciprofloxacin, erythromycin, doxycycline, and chloramphenicol respectively.

Six of the isolates of MRSA (8.6\%) were resistant to five antimicrobial drugs and the resistant patterns were cefoxitin/erythromycin/doxycycline/penicillin/ chloramphenicol.

\section{Conclusion}

Methicillin-resistant $S$. aureus was isolated from both medical and non-medical area. Even though there was no statistically significant difference, the proportion of MRSA isolated from the medical area was two times higher than the non-medical area. Participants who were unable to write and read and those who have at most service year were presented to acquire more MRSA and have the statistically significant difference.

More than 30\% of confirmed MRSA isolates were resistant to most of the antimicrobial drugs tested in the present study; however, no resistance was recorded from ciprofloxacin.

Janitors who were unable to write and, having more services and serving in the hospital should get awareness on the impact of MRSA and its transmission especially in relation to the hospital patients during cleaning of inpatient rooms.

\section{Limitations}

This study limited to conduct the MRSA gen as well as some additional antimicrobial agents.

\footnotetext{
Abbreviations

S. aureus: Staphylococcus aureus; MRSA: methicillin resistance Staphylococcus aureus; SPSS: Statistical Package for Social Sciences; MDR: multidrug resistance; ERC: Ethical Review Committee; USA: United States of America; Cl: confidence interval; ATCC: American type culture collection; CLSI: Clinical Laboratory Standards Institute.
} 


\section{Authors' contributions}

AGk, DGH, GKA, and TAM involved in designing of the project, collection of data, data analysis and interpretation, and write up of the manuscript. AGK and DGH designed the study, supervised data collection both on field and in laboratory, and prepared the manuscript for publication. All authors read and approved the final manuscript.

\section{Acknowledgements}

We would like to thank officials and study participants of the study sites for their cooperation during data collection by providing and/or facilitating the collection of valuable information.

\section{Competing interests}

The authors declare that they have no competing interests.

\section{Availability of data and materials}

All data analyzed during this study are included in the published article.

\section{Consent for publication}

Not applicable.

\section{Ethics approval and consent to participate}

The study was ethically approved by the Ethical Review Committee of Mekelle University College of Health Sciences. Informed consent was collected from each study participants after they understood the aim of the study.

\section{Funding}

Mekelle University (CRPO/CHS/015/08).

\section{Publisher's Note}

Springer Nature remains neutral with regard to jurisdictional claims in published maps and institutional affiliations.

Received: 1 November 2017 Accepted: 3 May 2018

Published online: 11 May 2018

\section{References}

1. Murray PR, Rosenthal KS, Pfaller MA. Medical microbiology. 5th ed. Philadelphia: Elsevier Mosby; 2013. p. 332-3.

2. DeLeo FR, Otto M, Kreiswirth BN, Chambers HF. Communityassociated methicillin-resistant Staphylococcus aureus. Lancet. 2010;375(9725):1557-68.

3. Kejela T, Bacha K. Prevalence and antibiotic susceptibility pattern of methicillin-resistant Staphylococcus aureus (MRSA) among primary school children and prisoners in Jimma Town, Southwest Ethiopia. Ann Clin Microbiol Antimicrob. 2013;12:11.

4. Hidron Al, Edwards JR, Patel J, Horan TC, Sievert DM, Pollock DA, Fridkin SK. Antimicrobial-resistant pathogens associated with healthcareassociated infections: annual summary of data reported to the national healthcare safety network at the centers for disease control and prevention, 2006-2007. Infect Control Hosp Epidemiol. 2008;29(11):998-1008.

5. Suaya JA, Mera RM, Cassidy A, Hara PO, Amrine-Madsen H, Burstin S, Miller LG. Incidence and cost of hospitalizations associated with Staphylococcus aureus skin and soft tissue infections in the United States from 2001 through 2009. BMC Infect Dis. 2014;14:296.
6. Sabra SM, Abdel-Fattah MM. Epidemiological and microbiological profile of nosocomial infection in Taif Hospitals, KSA (2010-2011). World J Med Sci. 2012:7(1):1-9.

7. Mulul W, Kibru G, Beyene G, Meku D. Postoperative nosocomial infections and antimicrobial resistance pattern of bacteria isolates among patients admitted at Felege Hiwot Referral Hospital, Bahirdar, Ethiopia. Ethiop J Health Sci. 2012;22:7-17.

8. Iyer AP, Baghallab I, Albaik M, Kumosani T. Nosocomial infections in Saudi Arabia caused by methicillin resistance Staphylococcus aureus (MRSA). Clin Microbial. 2014;3:3

9. Cornejo-Juarez P, Vilar-Compte D, Perez-Jimenez C, Namendys-Silva SA, Sandoval-Hernandez S, Volkow-Fernandez P. The impact of hospitalacquired infections with multidrug-resistant bacteria in an oncology intensive care unit. Int J Infect Dis. 2015:31:31-4

10. Ray GT, Suaya JA, Baxter R. Incidence, microbiology, and patient characteristics of skin and soft-tissue infections in a US population: a retrospective population-based study. BMC Infect Dis. 2013;13:252.

11. Chen C, Huang Y. Community-acquired methicillin-resistant Staphylococcus aureus in Taiwan. J Microbiol Immunol Infect. 2005;38:376-82.

12. Mongkolrattanotha K, Daum RS. Impact of community-associated, methicillin-resistant Staphylococcus aureus on management of the skin and soft tissue infections in children. Curr Infect Dis Rep. 2005;7:381-9.

13. Adler A, Givon-Lavi N, Moses AE, Block C, Dagan R. Carriage of community-associated methicillin-resistant Staphylococcus aureus in a cohort of infants in Southern Israel: risk factors and molecular features. J Clin Microbiol. 2010;48(2):531-8

14. Chang CJ, Chen NC, Lao CK, Huang YC. Nasal Staphylococcus aureus and methicillin-resistant S. aureus carriage among janitors working in hospitals in Northern Taiwan. PLoS ONE. 2015;10(9):1-11.

15. Rashid Z, Farzana K, Sattar A, Murtaza G. Prevalence of nasal Staphylococcus aureus and methicillin-resistant Staphylococcus aureus in hospital personnel and associated risk factors. Acta Poloniae Pharm Drug Res. 2012;69(5):985-91.

16. Askarian M, Zeinalzadeh A, Japoni A, Alborzi A, Memish ZA. Prevalence of nasal carriage of methicillin-resistant Staphylococcus aureus and its antibiotic susceptibility pattern in healthcare workers at Namazi Hospital, Shiraz, Iran. Int J Infect Dis. 2009;13:241-7.

17. Shibabaw A, Abebe T, Mihret A. Nasal carriage rate of methicillin resistant Staphylococcus aureus among Dessie Referral Hospital Health Care Workers; Dessie, Northeast Ethiopia. Antimicrob Resist Infect Control. 2013;2:25.

18. Balta B, Derbie F. Nasal carriage of methicillin resistant Staphylococcus aureus strains among inpatients of Jimma Hospital, South Western Ethiopia. Ethiop J Health Sci. 2003;13(2):107-16.

19. Gebreyesus A, Gebre-Selassie S, Mihert A. Nasal and hand carriage rate of methicillin resistant Staphylococcus aureus (MRSA) among health care workers in Mekelle Hospital, North Ethiopia. Ethiop Med J. 2013:51:41-7.

20. The performance of Mekelle University in 2014/2015, Annual report; 2015.

21. Cheesbrough M. District laboratory practice in tropical countries. 2 nd ed. New York: Cambridge University Press; 2006. p. 179-82.

22. Koneman EW, Allen SD, Schreckenberger PC, Winn WC. Color atlas and text book of diagnostic microbiology. 5th ed. Philadelphia: Lippincott Williams and Wilkins; 1997. p. 171-241.

23. CLSI. Performance standards for antimicrobial susceptibility testing. CLSI approved standard M100-S23. Wayne: Clinical and Laboratory Standards Institute; 2013 